\title{
EDITORIAL
}

\section{Planificación Móvil: Nuevos Enfoques de la Dirección Estratégica en las Instituciones de Educación Superior}

El mundo evoluciona y la forma de dirigir las organizaciones también, de hecho, los modelos de dirección estratégica que guiaban a las instituciones han cambiado, debido a que los enfoques tradicionales impiden ajustarse a las transformaciones del entorno. En concreto, un modelo de dirección estratégica es un esquema que reúne los principales elementos que debe considerar la organización, para implementar su proceso de planificación, proceso utilizado por todo tipo de instituciones ${ }^{1}$ (Cuesta, 2012), e involucra determinadas etapas que van desde el análisis estratégico, pasando por la formulación de las estrategias, hasta terminar con la implementación de las mismas ${ }^{2}$ (Guerras y Navas, 2015). Ciertamente, algunos modelos contemplan una mayor o menor desagregación, en cuanto a sus elementos o etapas fundamentales, sin embargo, todos reafirman el actual paradigma de dirección estratégica que siguen las organizaciones. Asimismo, precedieron a este paradigma, otros modelos, como son el de dirección por control, orientado principalmente al control de los presupuestos, seguido del modelo de dirección por extrapolación, en donde cobra fuerza el control de gestión, y, actualmente, el modelo dominante es la dirección por anticipación, o el modelo de dirección estratégica de las organizaciones. No obstante, este último está dando señales de estar en su etapa final, queriendo dar paso al modelo ya anunciado en el área de dirección, como es el de respuestas rápidas y flexibles. De hecho, existen metodologías precursoras a este último, como son los métodos prospectivos, tales como el método de los escenarios, el método Delfhi y el método de los escenarios cruzados, sin embargo, éstos no recogen todos los elementos necesarios para ser considerados un nuevo paradigma en la gestión de las instituciones, pero sí han contribuido a la transición entre ambos enfoques. En definitiva, en la actualidad, los cambios que ocurren son cada vez más constantes y rápidos, lo cual impulsa a que las instituciones entreguen respuestas más rápidas y flexibles ante las nuevas demandas de los usuarios o stakeholders.

De hecho, Lucena ${ }^{3}$ (2014:106-112) plantea que las organizaciones buscan dar respuestas apropiadas a los cambios económicos, políticos y sociales y, que además, la estructura universitaria requiere adecuarse al proceso de cambio que vive el mundo globalizado actual, donde se reclaman procesos más rápidos, oportunos y con capacidad de respuesta ante la demanda del entorno. De manera similar, Rodríguez-Ponce 4 (2016: 541) refuerza que "los tiempos que asoman para el sistema universitario chileno son de mayores exigencias en múltiples frentes y dimensiones".

Asimismo, la evolución de los modelos también obedece a que las organizaciones se han vuelto cada vez más complejas y dinámicas, abordando diferentes ámbitos de actuación en diversos contextos organizacionales, recibiendo a su vez, requerimientos de actores que se relacionan con ella, y que debido a la velocidad de la innovación y al desarrollo de las tecnologías, sus mentes se han acostumbrado a

1 U. Cuesta. "Planificación Estratégica y Creatividad". ESIC Editorial. 1ª Edición. pp. 35-41. Madrid, España. ISBN: 978-847356-863-0. 2012.

2 L.A. Guerras-Martín y J.E. Navas-López. "La Dirección Estratégica de la Empresa. Teoría y Aplicaciones”. Civitas. 5 a Edición, pp. 11-25. Madrid, España. ISBN: 9788447053001. 2015.

3 Y.P. Lucena. "Visión analítica de la planificación prospectiva en las universidades públicas venezolanas". Cuadernos de Administración. Vol. 30 N 52, pp. 105-114. 2014. ISSN: 0120-4645. DOI: http://www.redalyc.org/articulo.oa?id=225033236011.

4 E. Rodríguez-Ponce "La relevancia de la perspectiva estratégica en la dirección de las universidades". Ingeniare. Revista chilena de ingeniería. Vol. 24 No 4, pp. 538-539. 2016. ISSN: 0718-3305. DOI: https://dx.doi.org/10.4067/S0718-33052016000400001. 
demandar respuestas más rápidas a sus solicitudes. Bajo este escenario es normal preguntarse, si los modelos tradicionales que guían en la actualidad a las instituciones permiten responder a estas nuevas exigencias, y, si estas exigencias, están alineadas a los actuales sistemas y procesos que poseen las organizaciones. Es precisamente en este punto en donde se vislumbra un desafío para las instituciones de educación superior, porque, en particular, estas instituciones no sólo son las generadoras de conocimiento, volviéndose en el semillero de los desarrollos que impulsan las nuevas demandas, sino también, son quienes transfieren este conocimiento a las nuevas generaciones, $\mathrm{y}$, por ende, contribuyen a los patrones de demandas y los nuevos requerimientos que la comunidad exige a las organizaciones. De igual forma, los aspectos del entorno, como la reforma de educación superior, las leyes y normativas, y, las demandas del medio por procesos formativos más alineados a los tiempos actuales, requieren de un modelo que sea capaz de adaptarse a estas nuevas realidades y poder responder con velocidad ante ellas. Es por esta razón, que surge el concepto de planificación móvil, al alero del naciente modelo de respuestas rápidas y flexibles. En definitiva, se entenderá por planificación móvil, a un proceso de planificación estratégica de carácter móvil y flexible que permite la adaptación a los cambios internos y/o externos que ocurren en el entorno, considerando para ello un horizonte de largo plazo, la reformulación o ajustes estratégicos, al igual que su seguimiento.

En síntesis, y considerando las tendencias del entorno y la trayectoria en materia de planificación de las instituciones de educación superior, un desafío para ellas es continuar avanzando en dinamizar y flexibilizar este proceso, para poder ir adaptándose a los cambios que ocurran, y, para ello, es necesario generar una nueva modalidad para la gestión de los planes estratégicos, incorporando el concepto de planificación estratégica móvil, lo que implica realizar ajustes a la planificación, evaluar su cumplimiento y el periodo de tiempo, con el propósito de proyectar las potenciales mejoras, en función de los nuevos desafíos y/o escenarios que posea la institución.

\author{
Dra. Patricia Huerta-Riveros \\ Universidad del Bío-Bío \\ Facultad de Ciencias Empresariales \\ Concepción, Chile \\ phuerta@ubiobio.cl
}

\author{
Dra. Liliana Pedraja-Rejas \\ Universidad de Tarapacá \\ Escuela de Ingeniería Industrial, \\ Informática y de Sistemas \\ Arica, Chile \\ lpedraja@uta.cl
}

